\title{
CORRELATIONS FOR NATURAL CONVECTIVE HEAT TRANSFER FROM VERTICAL AND INCLINED CYLINDERS
}

\author{
Abdulrahim Kalendar ${ }^{1}$, Sayed Karar ${ }^{1}$, Ahmad Kalendar ${ }^{1}$, Patrick Oosthuizen ${ }^{2}$
}

${ }^{1}$ Dept. of Mechanical Power and Refrigeration

College of Technological Studies-PAAET, Shuwaikh, Kuwait

${ }^{2}$ Dept. of Mechanical and Materials Engineering

Queen's University, Kingston, ON, Canada, K7L 3N6

This is an Accepted Manuscript of an article published by Taylor \& Francis in Heat Transfer Engineering on 2017-01-02 available online: https://doi.org/10.1080/01457632.2016.1156413 
${ }^{1}$ Corresponding author, Abdulrahim Kalendar, P.O.Box:36771, Code:24758, Alras, Kuwait, Email: ay.kalendar1@ @ paaet.edu.kw, kalendar@ hotmail.com, Tel.:(965)22314232, Mobile:(965)66677354, Fax:(965)24811753

Abstract

Natural convective heat transfer from the exposed top surface of an inclined isothermal cylinder, with a circular cross-section, mounted on a flat adiabatic base plate has been numerically investigated. The cylinder is mounted normal to the flat adiabatic base plate. The numerical solution has been obtained by solving the dimensionless governing equations, subject to boundary conditions, using the commercial finite volume method based code FLUENT. The flow has been assumed to be symmetrical about the vertical center-plane through the cylinder. Results have only been obtained for Prandtl number of 0.7, this being the value existing in the application that originally motivated this study. The simulations consider Rayleigh numbers between $10^{3}$ and $10^{7}$, inclination angles between $0^{\circ}$ and $180^{\circ}$, and dimensionless cylinder diameters between 0.25 and 1 . The effects of dimensionless diameter, Rayleigh numbers, and inclination angles on the mean Nusselt number for the top exposed surface of the cylinder have been studied. Empirical correlations for the heat transfer rates from the top exposed surface of the cylinder have been derived.

\section{Introduction}

The growth in electronic device density and operating speed demands the development of effective thermal management and cooling schemes. Many components used in electronic cooling situations that arise in non-computer applications such as those that exist in measurement and control systems can be approximately modeled as involving natural convective heat transfer from an inclined cylinder with a circular cross- 
section mounted on a flat adiabatic base plate. The primary objective of the present study is to numerically investigate the natural convective heat transfer rates from such cylinders. Furthermore, the other cylinder surfaces are exposed to the surrounding air. A depiction of this flow situation being considered is shown in Figure 1. The numerical study presented in this study therefore investigates the heat transfer rate from the exposed top surface of the cylinder at various angles of inclination between the vertically upwards and vertically downwards as shown in Figure 2. The influence of the cross-sectional sizeto-length ratio of the cylinder, i.e., $D / h$, and the mean heat transfer rate emanating from the side surface of the cylinder on the mean heat transfer rate from the exposed top surface of the cylinder at various angles of inclination have been thoroughly investigated.

The present study is an extension of the previous work described in [1-4] in which the heat transfer rates from the side surface of inclined short cylinders were investigated. The present work was undertaken to fully account for that interaction of the flow between the top exposed surface with the side surface of the cylinder at different angles of inclination and to investigate its effect on the convective heat transfer rates. An extensive set of empirical equations describing the results has been developed.

Natural convective heat transfer from vertical and horizontal cylinders has been extensively reviewed in the literature. A comprehensive study of this subject can be found in refs. [5-10]. However, most of these studies assume the length-to-diameter ratio of the cylinder is relatively large and utilize the boundary layer assumptions.

There have been a few limited studies of relatively short cylinders in which the interaction of the flows from the heated surfaces is possibly significant. More recently, an experimental study was undertaken by Kimura et al. [11]. They observed that the local 
heat transfer coefficients increase in both laminar and turbulent flow regions with decreasing diameter. Oosthuizen [12] experimentally studied the free convective heat transfer rates from vertical cylinders to air, with the cylinders attached to an insulated surface on one end and with the other end exposed and at the same temperature as the cylindrical side surface. Oosthuizen's main results indicate that the heat transfer rate from shorter cylinders with exposed ends in both orientations is lower than that from cylinders with insulated ends. A similar experimental study of heat transfer from horizontal cylinders with various length-to-diameter ratios, attached to an insulated surface on one end with the other end exposed and at the same temperature as the cylindrical surface, was undertaken by Oosthuizen and Paul [13]. Their results showed that the Nusselt number based on diameter increases as the length-to-diameter ratio decreases due to three dimensional flow effects. Natural convective heat transfer emanating from a vertical cylinder with an exposed horizontal top surface and constant surface temperature has been numerically investigated by Oosthuizen $[14,15]$. These investigations concluded that the mean Nusselt number for the heated top surface is much lower than that of the heated side surface. Consequently, the heated side surface is the dominant factor in determining the overall mean Nusselt number. Popiel et al. [16] obtained experimental results using a transient technique for the laminar free convective mean heat transfer rate from isothermal vertical slender cylinders where the top and bottom surfaces are insulated. Their results were obtained in air for Rayleigh numbers based on the height of the cylinder in the range $1.5 \times 10^{8}<R a<1.1 \times 10^{9}$ and for dimensionless heights of $0<h / D<60$. Even with the smallest $h / D$ cylinder, the heat transfer coefficients were found to be higher than the values predicted assuming flow over a wide flat plate. 
A few studies concerned with natural convective heat transfer from inclined short cylinders have been undertaken. For example Oosthuizen [17] experimentally investigated free convective heat transfer in air from inclined cylinders where the both ends of the cylinders are insulated. He derived empirical equations to evaluate the Nusselt number for an inclined cylinder. Al-Arabi and Salman [18] and Al-Arabi and Khamis [19] experimentally studied natural convective heat transfer from inclined cylinders with various length-to-diameter ratios. The authors found that the heat transfer rate depends on both the diameter and the inclination angle. They also discovered that the length of the laminar flow region increased with increased angle of inclination from the horizontal. Oosthuizen and Mansingh [20] experimentally studied free and forced convective heat transfer from short inclined cylinders. They found that the ratio of the length to the diameter of the cylinder has a significant effect on the free convective heat transfer rate from short cylinders where end effects cause a rise in the heat transfer rate with decreasing length-to-diameter ratio and they provided a correlation equation that can be used to calculate the mean Nusselt number. Natural convective heat transfer rate from short isothermal inclined downward pointing cylinders with exposed ends in air has been studied by Oosthuizen and Paul $[21,22]$. Their results indicated that the heat transfer rate from cylinders with exposed ends is lower than that from cylinders with insulated ends with the difference increasing with decreasing length-to-diameter ratio. Moreover, the heat transfer rates from short cylinders with exposed ends pointing downward are very close to those for short cylinders with exposed ends pointing upwards.

Most of these previous studies have considered a relatively narrow range of the governing parameters and none gives much information about the effect of the interaction 
of the flow from the heated side wall of the cylinder with the flow over top heated end of the cylinder for different angles of inclination relative to the vertical. There still therefore exists a need for a broader range of results that can be used as the basis for predicting heat transfer rates in practical situations involving the type of flow here being considered.

\section{Numerical solution procedure}

The solution domain used in obtaining the numerical solution is shown in Figure 3. The flow has been assumed to be symmetric about the vertical center plane EFNOSICDE shown in Figure 3 and to be steady and laminar. It has also been assumed that the fluid properties are constant except for the density change with temperature which gives rise to the buoyancy forces, this being treated here by using the Boussinesq approach. The governing equations have been written in dimensionless form using the length, $h$, of the cylinder as the length scale and $T_{w}-T_{F}$ as the temperature scale, $T_{w}$ being the temperature of surface of cylinder and $T_{F}$ being the fluid temperature far from the cylinder. The following reference velocity has been introduced:

$$
u_{r}=\frac{\alpha}{h} \sqrt{\operatorname{RaPr}}
$$

Where $P r$ is the Prandtl number and $R a$ is the Rayleigh number based on $h$, i.e.:

$$
R a=\frac{\beta g\left(T_{w}-T_{F}\right) h^{3}}{v \alpha} \quad, \operatorname{Pr}=\frac{v}{\alpha}
$$

The following dimensionless variables have then been defined:

$$
\begin{aligned}
& X=\frac{x}{h}, Y=\frac{y}{h}, Z=\frac{z}{h}, U_{X}=\frac{u_{x}}{u_{r}}, \\
& U_{Y}=\frac{u_{y}}{u_{r}}, U_{Z}=\frac{u_{z}}{u_{r}}, P=\frac{\left(p-p_{F}\right) h}{\mu u_{r}}, \theta=\frac{T-T_{F}}{T_{w}-T_{F}}
\end{aligned}
$$


where $T$ is the fluid temperature, $T_{w}$ is the temperature of the hot cylinder surface and $T_{F}$ is the fluid temperature far from the cylinder. As shown in Figure 3, the $z$-coordinate is measured along the axis of the cylinder and the $x$ - and $y$-coordinates are measured in the plane of the flat adiabatic base plate. In terms of these dimensionless variables if $\phi$ is the angle from the vertical at which the cylinder is inclined the governing equations are the following:

$\frac{\partial U_{X}}{\partial X}+\frac{\partial U_{Y}}{\partial Y}+\frac{\partial U_{Z}}{\partial Z}=0$

$U_{X} \frac{\partial U_{X}}{\partial X}+U_{Y} \frac{\partial U_{X}}{\partial Y}+U_{Z} \frac{\partial U_{X}}{\partial Z}=\sqrt{\frac{P r}{R a}}\left(-\frac{\partial P}{\partial X}+\frac{\partial^{2} U_{X}}{\partial X^{2}}+\frac{\partial^{2} U_{X}}{\partial Y^{2}}+\frac{\partial^{2} U_{X}}{\partial Z^{2}}\right)+\theta \sin \phi$

$U_{X} \frac{\partial U_{Y}}{\partial X}+U_{Y} \frac{\partial U_{Y}}{\partial Y}+U_{Z} \frac{\partial U_{Y}}{\partial Z}=\sqrt{\frac{P r}{R a}}\left(-\frac{\partial P}{\partial Y}+\frac{\partial^{2} U_{Y}}{\partial X^{2}}+\frac{\partial^{2} U_{Y}}{\partial Y^{2}}+\frac{\partial^{2} U_{Y}}{\partial Z^{2}}\right)$

$U_{X} \frac{\partial U_{Z}}{\partial X}+U_{Y} \frac{\partial U_{Z}}{\partial Y}+U_{Z} \frac{\partial U_{Z}}{\partial Z}=\sqrt{\frac{P r}{R a}}\left(-\frac{\partial P}{\partial Z}+\frac{\partial^{2} U_{Z}}{\partial X^{2}}+\frac{\partial^{2} U_{Z}}{\partial Y^{2}}+\frac{\partial^{2} U_{Z}}{\partial Z^{2}}\right)+\theta \cos \phi$

$U_{X} \frac{\partial \theta}{\partial X}+U_{Y} \frac{\partial \theta}{\partial Y}+U_{Z} \frac{\partial \theta}{\partial Z}=\frac{1}{\sqrt{R a P r}}\left(\frac{\partial^{2} \theta}{\partial X^{2}}+\frac{\partial^{2} \theta}{\partial Y^{2}}+\frac{\partial^{2} \theta}{\partial Z^{2}}\right)$

Because the flow has been assumed to be symmetric about the vertical centerplane of the cylinder, the domain used in obtaining the solution is as shown in Figure 3. The assumed boundary conditions on the solution in terms of the dimensionless variables are that for all the cylinder surfaces the dimensionless velocity components are all equal to zero and the dimensionless temperature is equal 1 . On the adiabatic base the assumed boundary conditions are that all dimensionless velocities are equal to zero and that the dimensionless temperature gradient normal to all surfaces is equal to 0 . On the plane of symmetry the dimensionless velocity component normal to the plane is zero and the gradients normal to this plane of the remaining velocity components are zero. On the 
outer planes of the solution domain the dimensionless temperature is equal to zero and the velocity components in the plane of the surface are zeros.

The above dimensionless governing equations subject to the boundary conditions discussed above have been numerically solved using the commercial finite-volume solver, FLUENT. The dimensionless governing equations subject to the boundary conditions discussed above have been numerically solved using the commercial finite volume method based code, FLUENT. In the present study, the side surface of the cylinder used the Quad/map scheme and the exposed top surface used the Quad/Tri/Wedge scheme, while the cylinder volume was meshed with the hexahedron/map scheme and rest of the enclosure was meshed with hexahedron/cooper using GAMBIT. Close to the hot cylinder surfaces, the number of grid points or control volumes was increased to enhance the resolution and accuracy. To ensure the accuracy of the results presented extensive grid and convergence criterion independence testing was undertaken in previous work this being described in details in the previous work refs. [1$4]$.

It indicated that the heat transfer results presented here are to within $1 \%$ independent of the number of grid points and of the convergence-criterion used. Also the effect of the positioning of the outer surfaces of the solution domain (i.e., surfaces ABRH, BRSC, CSOF, AHOF and HRSO shown in Fig. 3) from the heated cylinder surfaces was also examined and the positions used in obtaining the results discussed here were chosen to ensure that the heat transfer results were independent to within $1 \%$ of this positioning. No convergence problems were observed, the average Nusselt number being found not to change by more than $1 \%$ for residual values below $10^{-4}$. For all cases to obtain 
convergence, each equation for mass and momentums have been iterated until the residuals fall below $10^{-4}$ while the energy equation has been iterated until the residual falls below $10^{-6}$. The pressure-based solver was used with the second-order upwind scheme for convective terms in the mass, momentum and energy equations. For pressure discretization, the Presto scheme has been employed while the SIMPLE-algorithm has been used for pressure-velocity coupling discretization.

The mean Nusselt number for the top exposed heated surface of cylinder is defined by:

$$
N u_{m t}=\frac{q^{\prime}{ }_{m t} h}{k\left(T_{w}-T_{F}\right)}
$$

where $q_{m t}^{\prime}$ is the mean heat transfer rate per unit area from the exposed top surface of the cylinder.

\section{Results}

The solution has the following parameters:

1. The Rayleigh number, $R a$, based on the length of the heated cylinder, $h$, and the overall temperature difference $T_{w}-T_{F}$.

2. The dimensionless diameter of the cylinder, $D_{h}=D / h$.

3. The Prandtl number, $\operatorname{Pr}$.

4. The inclination angle, $\phi$, of the cylinder.

Because of the applications that motivated this study, results have only been obtained

for $\operatorname{Pr}=0.7$. Rayleigh numbers between approximately $10^{3}$ and $10^{7}$, dimensionless diameter ratios of between 1 and 0.25 and inclination angles of between $0^{\circ}$ and $180^{\circ}$. 
In order to validate the results a comparison between the present results when $h=0$, i.e., for flow over a circular surface in the same plane as the surrounding adiabatic surface with existing correlation equations for this situation has been considered. Some typical results for this situation are shown in Figures 4 and 5 for the cases where the circular surface is facing upwards and downwards, respectively. The variations given by empirical equations for this flow situation given in Table 1 are also shown in these figures. It will be seen that there is good agreement between the correlation equation given by Kakac and Yener [6] and the numerical results, where the differences of the mean Nusselt number are between $13.3 \%$ and $1.8 \%$ for the upward facing surface. For the downward facing surface the differences of the mean Nusselt number between the correlation equation given by Sucec [8] and the numerical results are between $2.6 \%$ and $1.2 \%$. It will also be seen that the correlation equation cannot be used to predict the heat transfer rate when the dimensionless diameter, $D_{h}=D / h$, is greater than zero. This is because for the upward facing and the downward facing cylinder cases there is an interaction of the flow along the heated side surface of the cylinder with the flow over the "top" heated surface.

Typical variations of the mean Nusselt number for the top surface with changing angles of inclination for various values of $D_{h}$ and $R a$ are shown in Figures 6 and 7, respectively. The results indicate that $N u_{m t}$ is approximately inversely proportional to the dimensionless cylinder diameter $D_{h}$ at all angles of inclination considered. Evidentially, $N u_{m t}$ increases for all Rayleigh numbers considered as the angle of inclination increases to about $\phi<180^{\circ}$. The highest value of $N u_{m t}$ occurs when the cylinder is in a vertical position where the top surface is facing down, i.e., when $\phi$ is equal $180^{\circ}$, except for the case where 
$D_{h}=1$ and $R a \geq 10^{6}$. The angle of inclination has a greater influence on $N u_{m t}$ at the higher values of Rayleigh numbers as opposed to lower ones. As the cylinder is inclined relative to the vertical position the mean Nusselt number for the top surface of the cylinder $N u_{m t}$ plays a significant role in determining the overall heat transfer rate. When the cylinder is oriented at angles between $0^{\circ}$ and $70^{\circ}-80^{\circ}$, the end-surface is embedded in the warm convection flow generated by the lateral surface of the cylinder which limits the actual temperature difference between the end-surface and the adjacent fluid. However the reverse is true for angles ranging between $100^{\circ}-110^{\circ}$ and for $180^{\circ}$ the warm convective flow that originates from the end- surface affects the heat transfer rate from the lateral surface of the cylinder.

The variations of the Nusselt numbers for the top surface and for the side surface with angle of inclination for $D_{h}$ equal to 1 and 0.25 and for $R a=10^{4}$ are shown in Figures 8 and 9 , respectively. It is evident from these results that the lowest values of the mean Nusselt number arises from the top surface as expected. This occurs when the top surface is facing up, i.e., when $\phi$ is equal to $0^{\circ}$, beyond which $N u_{m t}$ is proportional to $\phi$. The other extreme occurs when the angle of inclination reaches its maximum value when the heated top surface is facing down, i.e., when $\phi$ is equal to $180^{\circ}$. Although the mean heat transfer rate from the top heated surface, $N u_{m t}$, exhibits lower values than the mean heat transfer rate from the side heated surface, $N u_{m s}$, when $\phi$ is equal to $0^{\circ}$ it has a greater value than $N u_{m s}$ when $\phi$ is equal to $180^{\circ}$.

It is worth noting that the overall mean Nusselt number is essentially equal to the mean Nusselt number for the side surface at low values of $D_{h}$, as the ratio of the area of the top surface to that of the side surface is equal to $D_{h} / 4$. However, this scenario changes 
when the cylinder is inclined relative to the vertical position, resulting in a significant difference between the mean Nusselt number from the top surface of the cylinder relative to the mean Nusselt number from the side surface.

The changes in the three-dimensional flow patterns and in the flow interaction between the flow over the side surface of the cylinder and the flow over the top surface of the cylinder with angle of inclination are illustrated by the local Nusselt number distributions over the top heated surface shown in Figure 10, where the dimensionless local Nusselt number is defined as:

$$
N u_{L(T o p)}=\frac{q_{T o p}^{\prime} h}{k\left(T_{w}-T_{F}\right)}
$$

This figure shows the local Nusselt number distributions over the top surface of the cylinder for $D_{h}$ equal to 0.5 and for two values of Rayleigh numbers for different angles of inclination. The results given in this figure illustrate the effect of the angle of inclination on the interaction of the flow at different Rayleigh numbers on the top surface of the cylinder. As a result of the interaction of the flows over the side surface and the top surface of the cylinder, the changes of the Rayleigh number and angle of inclination cause a complex flow over the top surface. This figure shows regions of high and low local Nusselt number for different inclination angles and for different Rayleigh numbers.

The variation of the mean Nusselt number for the top surface relative to the mean Nusselt number for the side surface was discussed above. The relative importance of the heat transfer rate from the top surface compared to that from the vertical side surface of the cylinder will however depend both on the mean Nusselt numbers for the surfaces and on the relative surface areas of the cylinder. Now since: 


$$
A_{s}=\pi D h, \quad A_{t}=\frac{\pi}{4} D^{2}, \quad \text { and } A_{c}=\pi D h+\frac{\pi}{4} D^{2}
$$

where $A_{s}, A_{t}$, and $A_{c}$ are the dimensionless surface areas of the side of the cylinder, of the top surface of the cylinder and of the entire surfaces of cylinder respectively, it follows that:

$$
\frac{A_{s}}{A_{c}}=\frac{4}{D_{h}+4} ; \frac{A_{t}}{A_{c}}=\frac{D_{h}}{D_{h}+4} ; \frac{A_{t}}{A_{s}}=\frac{D_{h}}{4}
$$

The above relations indicate that over the range of values of $D_{h}$ considered here, i.e., 0.25 to $1, A_{t} / A_{s}$ is relatively small having a maximum value of 0.25 when $D_{h}=1$, i.e., the area of the top surface relative to the area of the vertical side surfaces remains comparatively small. As the angle of inclination increases from $0^{\circ}$ the interaction between the flow over the side surface of the cylinder and that over the top surface becomes significant and the effects of the top surface of the cylinder become more dominant and cannot be neglected, a portion of the side surface becoming less important. Now since:

$$
q_{m c}^{\prime} A_{c}=q_{m s}^{\prime} A_{s}+q_{m t}^{\prime} A_{t}
$$

It follows from the above equations that:

$$
N u_{m c}=N u_{m s}\left(\frac{A_{s}}{A_{c}}\right)+N u_{m t}\left(\frac{A_{t}}{A_{c}}\right)
$$

where $N u_{m s}, N u_{m t}$ and $N u_{m c}$ are the mean Nusselt numbers for the heated side surface, the top surface and the combination of side and top surface of the cylinder respectively. Hence, using Equation (12)

$$
N u_{m c}=N u_{m s}\left(\frac{4}{D_{h}+4}\right)+N u_{m t}\left(\frac{D_{h}}{D_{h}+4}\right)
$$


This equation indicates, as is to be expected, that $N u_{m c}$ tends to be equal $N u_{m s}$ at low values of $D_{h}$ and that it tends to be equal $N u_{m t}$ at large values of $D_{h}$. It will also be noted that:

$$
\frac{Q_{m c}}{Q_{m t}}=\frac{q_{m t}^{\prime} A_{c}}{q_{m t}^{\prime} A_{t}}=\frac{N u_{m c} A_{c}}{N u_{m t} A_{t}}=\frac{N u_{m c}}{N u_{m t}} \frac{4+D_{h}}{D_{h}}
$$

This equation allows $Q_{m} d Q_{m t}$ to be found using the calculated Nusselt number values. Some typical results so obtained are shown in Figure 11. From these results it can be seen that while $Q_{m d} / Q_{m t}$ is always greater than approximately 4 it is only at low values of $\phi$ that the contribution of $Q_{m t}$ to $Q_{m c}$ can be neglected. The assumption that the contribution of $Q_{m t}$ to $Q_{m c}$ can be neglected has sometimes been used in deriving correlation equations for the heat transfer rate from vertical cylinders using Eq.(15) and neglecting the second term on the right hand side. The present results show that this approach will not normally be applicable to the inclined cylinder case.

Consideration will next be given to the values of the mean Nusselt number of the top surface of cylinder, $N u_{m t}$. Because the size of the top surface, i.e., its diameter, will be the dimension that determines the heat transfer rate from this surface, the following are defined:

$$
N u_{m t D}=N u_{m t} D_{h} \quad \text { and } \quad R a_{D}=R a D_{h}^{3}
$$

Now both correlation equations for the case of an isothermal vertical cylinder, i.e., for $\phi=0^{\circ}$, when the heat transfer rate from the top surface is neglected and for the case of a horizontal cylinder, i.e., for $\phi=90^{\circ}$, for a Prandtl number of 0.7 have the form:

$$
N u_{m t D}=B R a_{D}^{n}
$$


The parameter $B$ is depending only on the Prandtl number of the fluid involved. When the cylinder is inclined at an angle to the vertical, the interaction of the flow between the surfaces that makeup the cylinder becomes important.

Fitting an equation of this form to the numerical results indicates that the present numerical results for the case of vertical and inclined isothermal heated cylinder, at different angles to the vertical with different dimensionless diameter, can indeed be approximately described by:

$$
N u_{m t D}=C R a_{D}^{n}
$$

where $C$ and $n$ are constants and their values are given in Table 2 .

Interestingly, the same form of equation as that given in Eq.(19) was given by of Kobus and Wedekind [23] in their correlation equations for an inclined circular disk between vertical and horizontal position.

A comparison between the results given by Eq.(19) and the numerical results are shown in Figures 12, 13, 14 and 15. This correlation equation was developed in the current research and can be used for a wide range of inclination angles. It can be seen that the correlation equation is in good agreement with the numerical results except for the case of a vertical cylinder, $\phi=0^{\circ}$, as shown in Figure 12, where the numerical results are scattered. The scatter in the results is due to the interaction between the flows over the cylindrical and top surfaces which is Rayleigh number dependent and due to the fact that the heat transfer from the hot top surface is dominantly by conduction this being especially true at the lower values of Rayleigh numbers considered. There is some interaction of the flow up the heated vertical side surface and the flow over the heated top surface which is not directly accounted here in deriving the correlation equation. The 
results given in Fig.13 shows that the maximum difference of the mean Nusselt number between the numerical results and the present correlation equation is $41.6 \%$, which occurs at the lowest value of Rayleigh number. While the differences are between $21.3 \%$ and $0.3 \%$ for all other values of Rayleigh numbers and dimensionless diameters considered in this study. The results given in Fig.14 shows that the differences of the mean Nusselt number between the numerical results and the present correlation equation are between $29 \%$ and $0.5 \%$ for all values of Rayleigh numbers and dimensionless diameters considered in this study. Figure 15 shows the results of Kobus and Wedekind [23] correlation equation for a circular disk which is based on experimental results and applies for the thickness to diameter ratios between 0.063 and 0.163 and for inclination angles of between the vertical and the horizontal position. Their correlation equation has uncertainty of less than $10 \%$. The present numerical and correlation results are in good agreement with the Kobus and Wedekind [23] correlation equation for the horizontal case where $\phi=90^{\circ}$. The differences of the mean Nusselt number between the present correlation equation and, the Kobus and Wedekind [23] correlation equation are between $9.3 \%$ and $3.9 \%$. While the differences of the mean Nusselt number between the numerical results and the present correlation equation are between $17.8 \%$ and $0.9 \%$ for all values of Rayleigh numbers and dimensionless diameters considered in this study.

\section{Conclusions}

Natural convective heat transfer from an isothermal inclined circular cylinder which has an exposed top surface and is, in general, inclined at an angle to the vertical between vertically upwards and vertically downwards has been numerically studied. The effects of dimensionless cylinder diameter, Rayleigh number, and inclination angle on the 
mean Nusselt number for the top surface of the cylinder was conducted in this study. The results of the present study indicate that:

1. In calculating the heat transfer rate from the entire circular cylinder the heat transfer rate from the top surface of the cylinder can be neglected when the dimensionless diameter, $D_{h}=D / h$, is less than 0.25 and the inclination angle, $\phi$, is less than about $40^{\circ}$.

2. The mean Nusselt number for the top surface of the circular cylinder increases as the inclination angle increases from the vertical position where the heated top surface is pointing upward.

3. The results obtained for the mean Nusselt number for the top surface for different angles of inclination can be adequately correlated by Eq.(19), except for the case of a vertical cylinder, i.e., for $\phi=0^{\circ}$. The observed scatter in these results arises from the following facts: (a) there is some interaction of the flow up the heated vertical side surface and the flow over the heated top surface which is not directly accounted for in deriving the correlation equation and (b) the heat transfer from the hot top surface is dominated by conduction heat transfer especially at lower values of Rayleigh numbers.

\section{Acknowledgment}

This work supported and funded by the Public Authority of Education and Training of Kuwait (PAAET). 


\section{Nomenclature}

$A_{c} \quad$ Dimensionless surface area of side and top surfaces of heated cylinder

$A_{s} \quad$ Dimensionless surface area of side surface of heated cylinder

$A_{t} \quad$ Dimensionless surface area of horizontal top of heated cylinder

A Surface area of cylinder, $\mathrm{m}^{2}$

$B \quad$ Constant used in correlation equation depending only on Prandtl number of fluid involved

C Constants used in correlation equation given in Table 2

D Diameter of cylinder, $\mathrm{m}$

$D_{h} \quad$ Dimensionless diameter of the cylinder, $D_{h}=D / h$

$g \quad$ Gravitational acceleration, $\mathrm{m} \cdot \mathrm{s}^{-2}$

$h \quad$ Length of heated cylinder, $\mathrm{m}$

$k \quad$ Thermal conductivity of fluid, $\mathrm{Wm}^{-1} \mathrm{~K}^{-1}$

$n \quad$ Power of Rayleigh number used in correlation equation given in Table 2

$N u_{D} \quad$ Mean Nusselt number based on $D$ and on $\left(T_{w}-T_{F}\right)$

$N u_{m c} \quad$ Mean Nusselt number of side and top heated surfaces of cylinder based on $h$ and on $\left(T_{w}-T_{F}\right)$

$N u_{m t D}$ Mean Nusselt number of the top surface of cylinder given by correlation equation based on diameter, $D$

$N u_{m t R}$ Mean Nusselt number of the horizontal top surface of cylinder based on radius, $R$

$N u_{L(T o p)}$ Local Nusselt number based on $h$ and on $\left(T_{w}-T_{F}\right)$ for the heated top surface of cylinder

$N u_{m s} \quad$ Mean Nusselt number for heated side surface of cylinder 
$N u_{m t} \quad$ Mean Nusselt number for heated top surface of cylinder

$\operatorname{Pr} \quad$ Prandtl Number

$P \quad$ Dimensionless Pressure

$p \quad$ Pressure, $\mathrm{Pa}$

$p_{F} \quad$ Pressure in undisturbed fluid, $\mathrm{Pa}$

$Q_{m c} \quad$ Mean heat transfer rate over heated surfaces of cylinder, W

$Q_{m t} \quad$ Mean heat transfer rate over top surface of heated cylinder, W

$q^{\prime} m c \quad$ Mean heat transfer rate per unit area over heated surfaces of cylinder, W.m ${ }^{-2}$

$q^{\prime} m s \quad$ Mean heat transfer rate per unit area over side surface of heated cylinder, W. $\mathrm{m}^{-2}$

$q^{\prime} m t \quad$ Mean heat transfer rate per unit area over top surface of heated cylinder, W. $\mathrm{m}^{-2}$

$q^{\prime}$ Top Local heat transfer rate per unit area over top surface of heated cylinder, W. $\mathrm{m}^{-2}$

$R \quad$ Radius of cylinder (D/2), m

$R a \quad$ Rayleigh number based on $h$ and temperature differences

$R a_{D} \quad$ Rayleigh number based on $D$ and temperature differences

$R a_{R} \quad$ Rayleigh number based on $R$

Tluid temperature, $\mathrm{K}$

$T_{F} \quad$ Fluid temperature far from the cylinder, $\mathrm{K}$

$T_{w} \quad$ Temperature of heated surfaces of cylinder, $\mathrm{K}$

$u_{r} \quad$ Reference velocity, $\mathrm{m} \cdot \mathrm{s}^{-1}$

$U_{X} \quad$ Dimensionless velocity component in $X$ direction

$u_{x} \quad$ Velocity component in $x$ direction, $\mathrm{m} . \mathrm{s}^{-1}$

$U_{Y} \quad$ Dimensionless velocity component in $Y$ direction

$u_{y} \quad$ Velocity component in $y$ direction, $\mathrm{m} . \mathrm{s}^{-1}$ 
$U_{Z} \quad$ Dimensionless velocity component in $Z$ direction

$u_{z} \quad$ Velocity component in $z$ direction, $\mathrm{m} . \mathrm{s}^{-1}$

X Dimensionless horizontal coordinate

$x \quad$ Horizontal coordinate, $\mathrm{m}$

Y Dimensionless horizontal coordinate

$y \quad$ Horizontal coordinate, $\mathrm{m}$

Z Dimensionless vertical coordinate

$z \quad$ Vertical coordinate, $\mathrm{m}$

\section{Greek Symbols}

$\alpha \quad$ Thermal diffusivity, $\mathrm{m}^{2} \cdot \mathrm{s}^{-1}$

$\beta \quad$ Bulk coefficient, $\mathrm{K}^{-1}$

$\mu \quad$ Dynamic Viscosity, N.s $/ \mathrm{m}^{2}$

$v \quad$ Kinematic viscosity, $\mathrm{m}^{2} \cdot \mathrm{s}^{-1}$

$\theta \quad$ Dimensionless temperature

$\phi \quad$ The angle of inclination of the cylinder relative to the vertical, Degrees 


\section{References}

[1] Kalendar, A., and Oosthuizen, P.H., Natural convective heat transfer from an inclined isothermal cylinder with an exposed top surface mounted on a flat adiabatic base, Proc. of IMECE/ASME International Mechanical Engineering Congress and Exposition November Lake Buena Vista, Florida, USA, Paper IMECE2009-12777, 10 pages, 2009.

[2] Kalendar, A., Oosthuizen, P.H., Alhadhrami, A., Experimental study of natural convective heat transfer from an inclined isothermal cylinder with an exposed top surface mounted on a flat adiabatic base, 8th International Conf. of Heat Transfer, Fluid Mechanics and Thermodynamics HEFAT, Pointe Aux Piments, Mauritius, South Africa. 8 pages, pp. 113-120, 2011.

[3] Kalendar, A., and Oosthuizen, P.H., Natural Convective Heat Transfer from short inclined Cylinders. Springer briefs in applied science and technology, thermal engineering and applied science, Springer, New York, ISBN 978-3-319-02459-2, 2013.

[4] Kalendar, A., Numerical and Experimental Studies of Natural Convective Heat Transfer from Vertical and Inclined Narrow Flat Plates and Short Cylinders, Ph.D. Thesis, Queen's University, Canada, 2011.

[5] Bejan, A., Convection Heat Transfer, 2nd ed., John Willey, New York, 1995.

[6] Kakac, S., and Yener, Y., Convective Heat Transfer, Second ed., CRC, Florida, USA, 1995.

[7] Yunus, A. Cengel, Heat Transfer, 1st ed., McGraw-Hill, New York, 1998.

[8] Sucec, J., Heat Transfer, 1st ed., Wm. C. Brown, Iowa, USA, 1985. 
[9] Kays, W., andCrawford, M., Convective Heat and Mass Transfer, Fourth ed., McGraw-Hill, New York, 2005.

[10] Martynenko, O.G., and Khramtsov, P.P., Free-Convective Heat Transfer, 1st ed., Springer, Berlin, 2005.

[11] Kimura, F., Tachibann, T., Kitamura, K., and Hosokawa, T., Fluid flow and heat transfer of natural convection around heated vertical cylinders (effect of cylinder diameter), JSME International Journal Series B: Fluids and Thermal Engineering, Vol. 47, no. 2, pp. 156-161, 2004.

[12] Oosthuizen, P.H., Free convective heat transfer from vertical cylinders with exposed ends, Transactions of the Canadian Society for Mechanical Engineering, Vol. 5, no. 4, pp. 231-234, 1979.

[13] Oosthuizen, P.H., and Paul, J.T., Free convective heat transfer from short horizontal cylinders, CANCAM 81: Comptes Rendus 8th Congres Canadien de Mecanique Appliquee Univ of Moncton, Faculty of Science \& Engineering, Moncton, NB, Can, pp. 711-712, 1981.

[14] Oosthuizen, P.H., Natural Convective Heat Transfer from a Vertical Cylinder with an Exposed Upper Surface, Proc. of the ASME-JSME Thermal Engineering Summer Heat Transfer Conf., Vancouver, BC, Paper HT2007-32135, 2007.

[15] Oosthuizen, P.H., Natural Convective Heat Transfer From an Isothermal Cylinder with an Exposed Upper Surface Mounted on a Flat Adiabatic Base with, ASME/IMECE International Mechanical Engineering Congress and Exposition, November 11-15, Seattle, Washington, USA, pp. 7, 2008. 
[16] Popiel, C.O., Wojtkowiak, J., and Bober, K., Laminar free convective heat transfer from isothermal vertical slender cylinder, Experimental Thermal and Fluid Science, Vol. 32, no. 2, pp. 607-613, 2007.

[17] Oosthuizen, P.H., Experimental Study of Free Convection Heat Transfer from Inclined Cylinders, ASME Journal of Heat Transfer, Vol. 98, pp. 672-674, 1976.

[18] Al-Arabi, M., and Salman, Y. K., Laminar Natural Convective Heat Transfer in the Laminar Region from Horizontal and Inclined Cylinders, International Journal of Heat and Mass Transfer, Vol. 7, pp. 45-51, 1980.

[19] Al-Arabi, M., and Khamis, M., Natural convection heat transfer from inclined cylinders, International Journal of Heat and Mass Transfer, Vol. 25, no. 1, pp. 315, 1982.

[20] Oosthuizen, P.H., and Mansingh, V., Free and forced convective heat transfer from short cylinders, Joint ASME/AIChE National Heat Transfer Conf. ASME, Seattle, WA, USA, 1983.

[21] Oosthuizen, P.H., and Paul, J.T., Natural Convective Heat Transfer from Inclined Downward pointing Cylinders with Exposed Ends, Proc. 2nd World Conference on Experimental Heat Transfer, Fluid Mechanics, and Thermodynamics, Dubrovnik, Yugoslavia, pp. 697-702, 1991.

[22] Oosthuizen, P.H., and Paul, J.T., Free Convective Heat Transfer from Short Inclined Cylinders, Experimental Heat Transfer, Fluid Mechanics and Thermodynamics, pp. 193-199, 1988.

[23] Kobus, C.J., and Wedekind, G.L., An empirical correlation for natural convection heat transfer from thin isothermal circular disks at arbitrary angles of 
inclination, International Journal of Heat and Mass Transfer, Vol. 45, pp. 1159-

$1163,2002$. 
Table 1 Empirical equations for natural convective heat transfer over uniform wall temperature (UWT) of circular cylinder

\begin{tabular}{|c|c|c|c|c|c|}
\hline $\begin{array}{l}\text { Authors } \\
\text { References }\end{array}$ & Conditions & $\begin{array}{c}\text { Pr } \\
\text { number }\end{array}$ & Range of $R a_{D}$ & Constants & Correlation Equations \\
\hline \multirow{2}{*}{$\begin{array}{c}\text { Kobus \& } \\
\text { Wedekind } \\
\text { [23] }\end{array}$} & \multirow{2}{*}{$\begin{array}{c}0^{\circ} \leq \phi \leq 90^{\circ} \\
0.068 \leq \mathrm{h} / \mathrm{D} \leq \\
0.63\end{array}$} & \multirow[b]{2}{*}{$\operatorname{Pr}=0.72$} & $2 \times 10^{2}-10^{4}$ & $\begin{array}{c}\mathrm{C}=1.795, \mathrm{a}=0.15 \\
\mathrm{~b}\left(\mathrm{deg}^{-1}\right)=2.22 \times 10^{-}\end{array}$ & \multirow[b]{2}{*}{$N u_{D}=C R a_{D}^{a-b \phi}$} \\
\hline & & & $10^{4}-3 \times 10^{7}$ & $\begin{array}{c}\mathrm{C}=0.9724, \\
\mathrm{a}=0.206, \mathrm{~b}\left(\mathrm{deg}^{-1}\right)= \\
1.33 \times 10^{-4}\end{array}$ & \\
\hline $\begin{array}{c}\text { Oosthuizen } \\
{[14]}\end{array}$ & $\begin{array}{c}\phi=0^{\circ} \\
0<\mathrm{D} / 2 \mathrm{~h} \leq 1.5\end{array}$ & $\operatorname{Pr}=0.7$ & $10^{4}<R a_{D}<10^{7}$ & 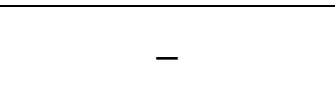 & $N u_{m t R}=0.45 R a_{R}^{0.16}$ \\
\hline $\begin{array}{c}\text { Kakac \& } \\
\text { Yener } \\
{[6]}\end{array}$ & $\begin{array}{c}\phi=0^{\circ} \\
\mathrm{h}=0\end{array}$ & $\operatorname{Pr}=0.72$ & $10^{5}<R a_{D}<10^{7}$ & - & $N u_{D}=0.54 R a_{D}^{0.25}$ \\
\hline $\begin{array}{c}\text { Kakac \& } \\
\text { Yener } \\
{[6]}\end{array}$ & $\begin{array}{c}\phi=180^{\circ} \\
h=0\end{array}$ & $\operatorname{Pr}=0.72$ & $\begin{array}{c}3 \times 10^{5}<R a_{D} \\
\quad<3 \times 10^{10}\end{array}$ & - & $N u_{D}=0.27 R a_{D}^{0.25}$ \\
\hline $\begin{array}{c}\text { Sucec } \\
{[8]}\end{array}$ & $\begin{array}{c}\phi=180^{\circ} \\
h=0\end{array}$ & $\operatorname{Pr}=0.72$ & $10^{6}<R a_{D}<10^{11}$ & - & $N u_{D}=0.58 R a_{D}^{0.2}$ \\
\hline
\end{tabular}


Table 2 Constants used in Eq.(19)

\begin{tabular}{ccc}
\hline$\phi$ & $\mathbf{C}$ & $\mathbf{n}$ \\
\hline $0^{\circ}$ & 0.8 & 0.12 \\
\hline $45^{\circ}$ & 0.65 & 0.21 \\
\hline $90^{\circ}, 135^{\circ}$ and $180^{\circ}$ & 1 & 0.21 \\
\hline
\end{tabular}




\section{List of Figure Captions}

Figure 1 Flow situation considered

Figure 2 Definition of inclination angles

Figure 3 Solution domain, where the rotation is about $y$-axis

Figure 4 Variation of mean Nusselt number with Rayleigh number for $h=0$ and $D=0.25$ $\mathrm{m}$ (i.e., for a circular plate embedded in a horizontal adiabatic surface) and for a dimensionless cylinder diameter, $D_{\mathrm{h}}=0.25$, for the case of an upward facing cylinder and a comparison of these results with that given by standard correlation equation for this situation

Figure 5 Variation of mean Nusselt number with Rayleigh number for $h=0$ and $D=0.25$ $\mathrm{m}$ (i.e., for a circular plate embedded in a horizontal adiabatic surface) and for a dimensionless cylinder diameter, $D_{\mathrm{h}}=0.25$, for the case of a downward facing cylinder and a comparison of these results with those given by standard correlation equations for this situation

Figure 6 Variation of mean Nusselt number for the top surface of cylinder with $\phi$, for various values of Rayleigh number and dimensionless cylinder diameter, $D_{\mathrm{h}}$

Figure 7 Variation of mean Nusselt number for the top surface of cylinder with $\phi$, for various values of Rayleigh number and dimensionless cylinder diameter, $D_{\mathrm{h}}$

Figure 8 Variation of mean Nusselt number for the individual surfaces that make up the cylinder $N u_{\mathrm{ms}}$ and $N u_{\mathrm{mt}}$ with $\phi$ for $R a=10^{4}$ and $D_{\mathrm{h}}=1$

Figure 9 Variation of mean Nusselt number for the individual surfaces that make up the cylinder $N u_{\mathrm{ms}}$ and $N u_{\mathrm{mt}}$ with $\phi$ for $R a=10^{4}$ and $D_{h}=0.25$

Figure 10 Variation of local Nusselt number $\boldsymbol{N} \boldsymbol{u}_{\boldsymbol{L}(\mathrm{Top})}$ based on $h$ over top side of the cylinder with different angles of inclination for $R a=10^{4}, R a=10^{6}$ and $D_{h}=0.5$ 
Figure 11 Variation of the ratio of the total heat transfer rate from the surfaces of the cylinder to the heat transfer rate from the top surface with angle of inclinations for $R a$ values of $10^{4}$ and $10^{6}$ and for $D_{h}=1$

Figure 12 Comparison of correlation equations for the top surface of the cylinder for $\phi=$ $0^{\circ}$ with the numerical results

Figure 13 Comparison of correlation equation for the top surface of the cylinder for $\phi=45^{\circ}$ with the numerical results

Figure 14 Comparison of correlation equation for the top surface of the cylinder for $\phi=90^{\circ}, 135^{\circ}$ and $180^{\circ}$ with the numerical results

Figure 15 Comparison of correlation equations for the top surface of cylinder for $\phi=90^{\circ}$ with the numerical results 


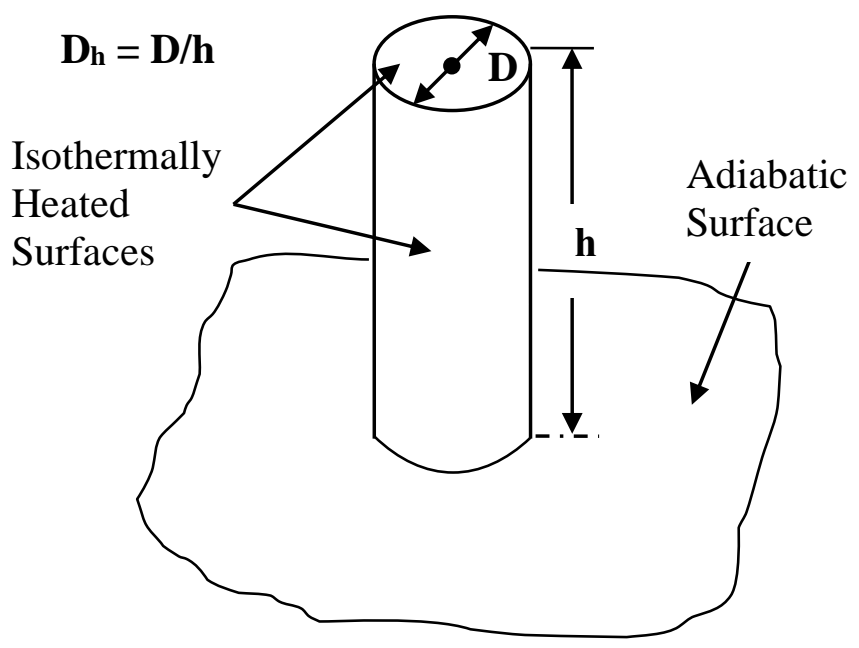

Figure 1 Flow situation considered 


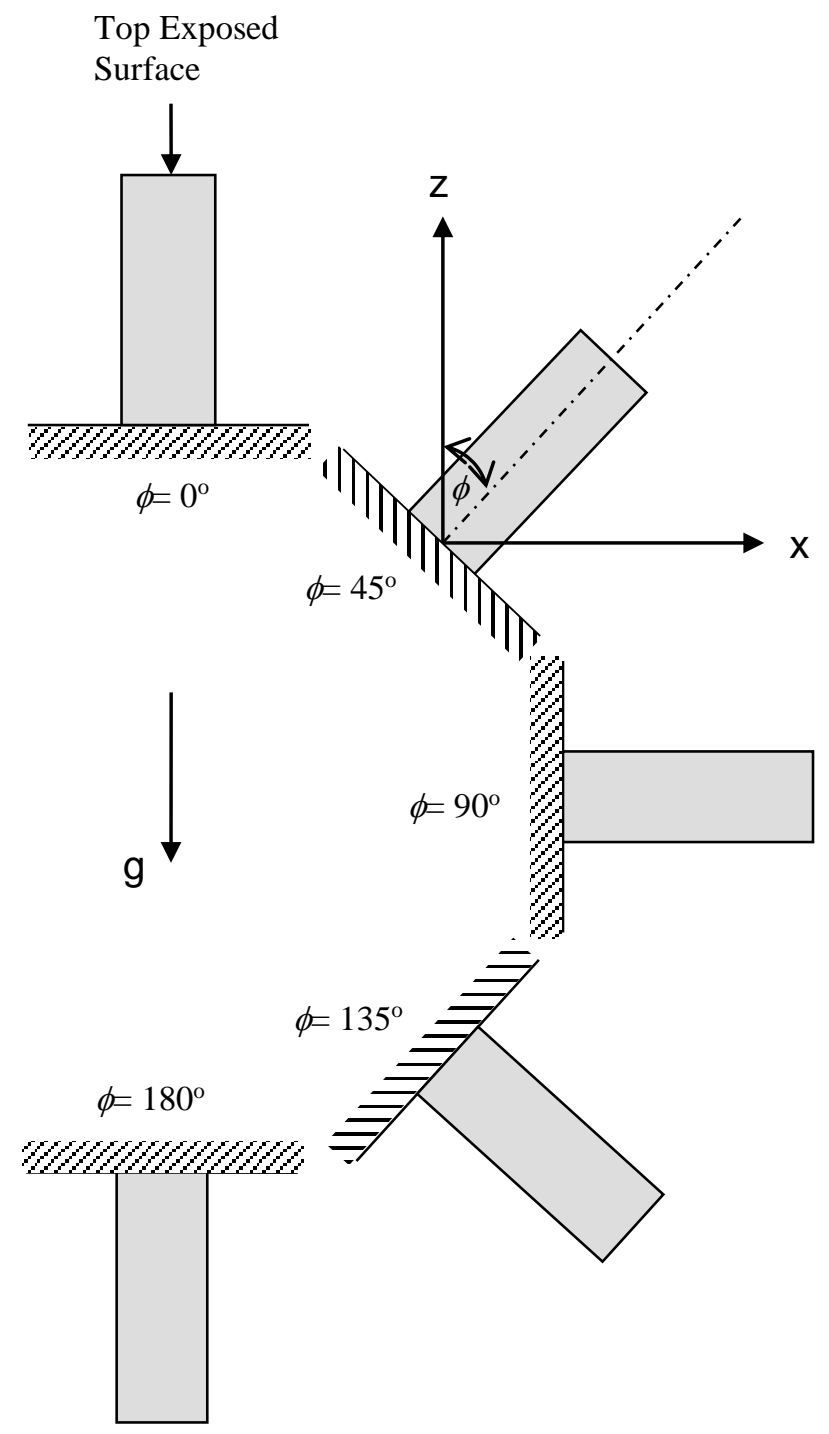

Figure 2 Definition of inclination angles 


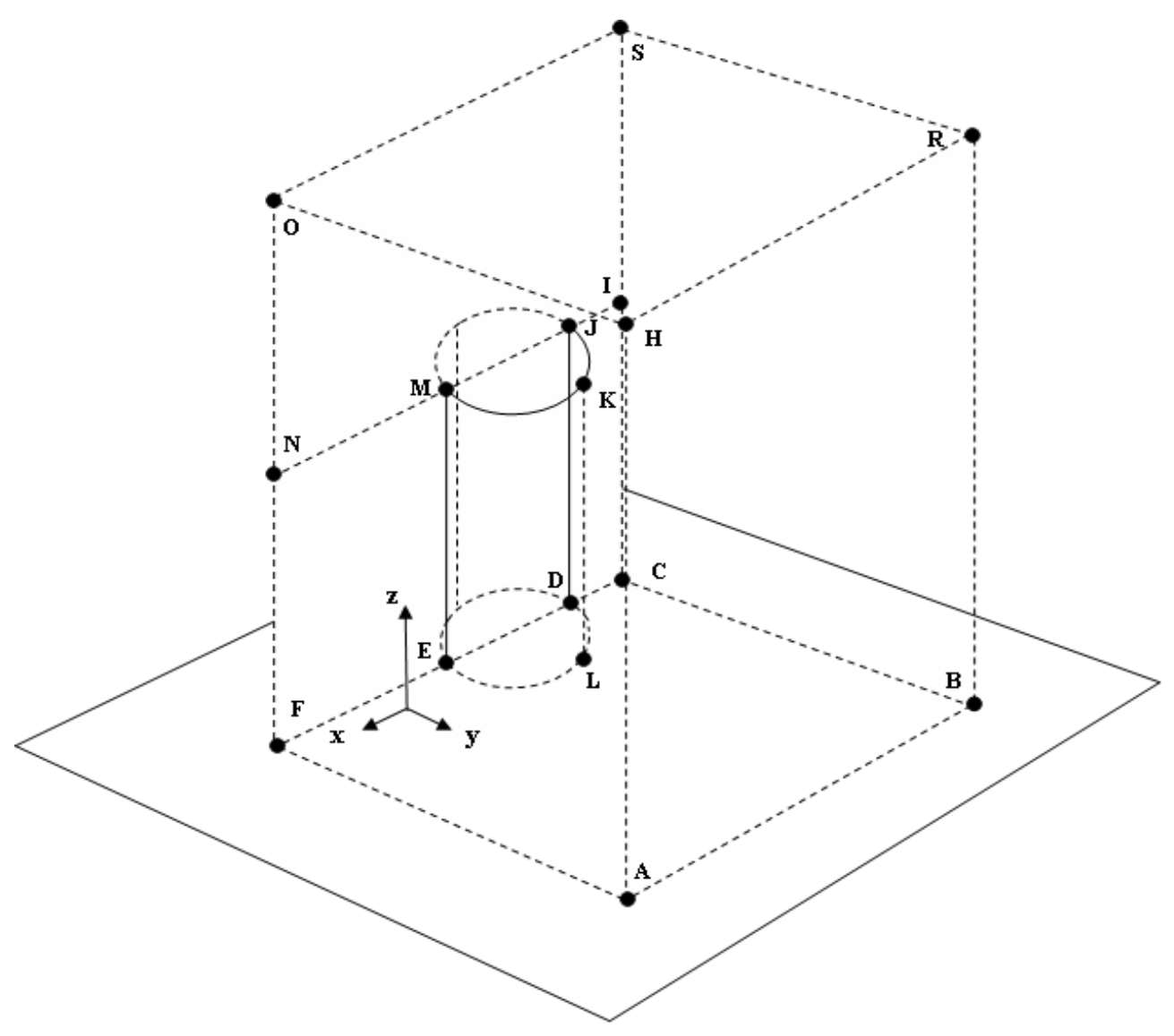

Figure 3 Solution domain, where the rotation is about $y$-axis 


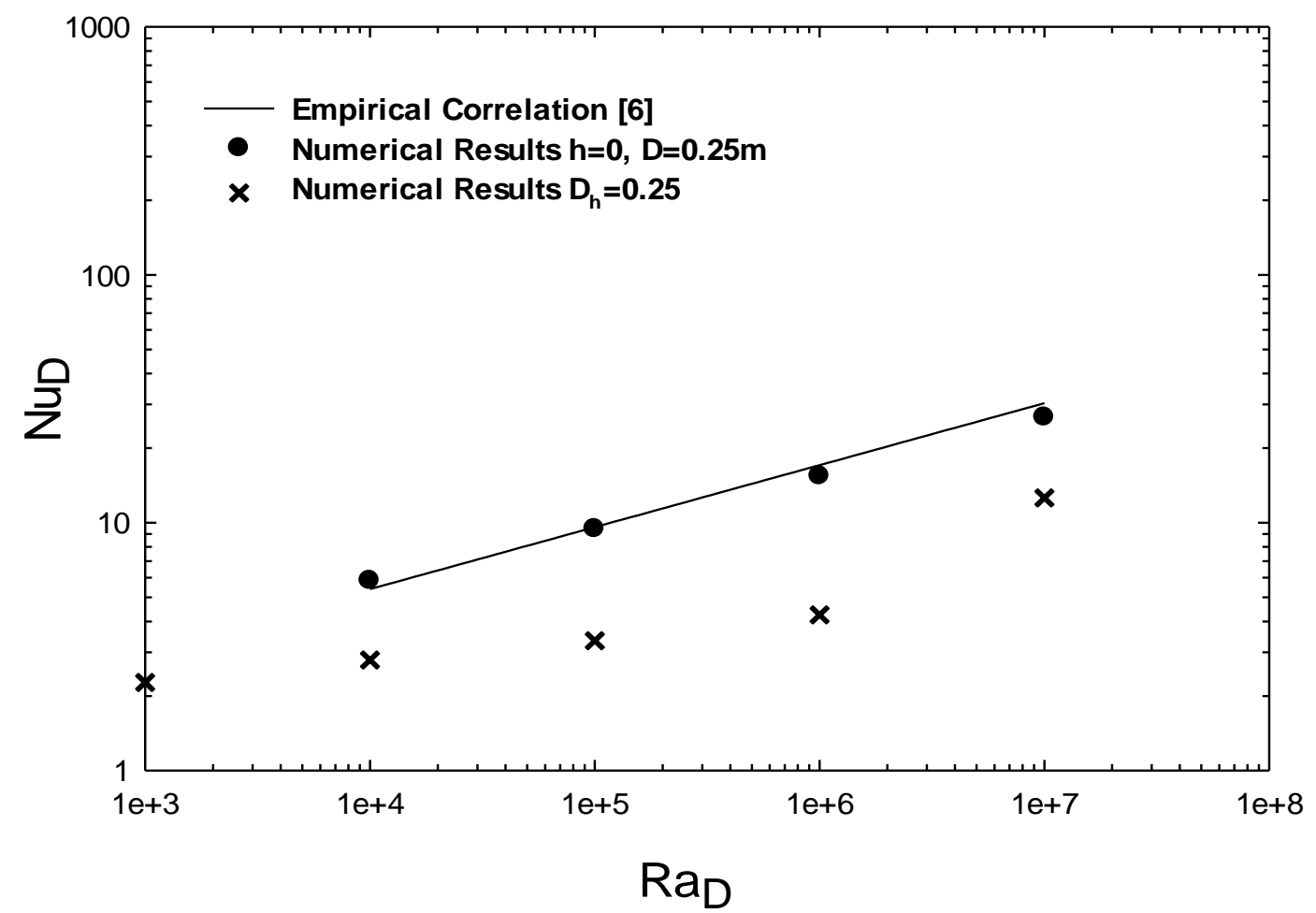

Figure 4 Variation of mean Nusselt number with Rayleigh number for $h=0$ and $D=0.25$ $m$ (i.e., for a circular plate embedded in a horizontal adiabatic surface) and for a dimensionless cylinder diameter, $D_{h}=0.25$, for the case of an upward facing cylinder and a comparison of these results with that given by standard correlation equation for this situation 


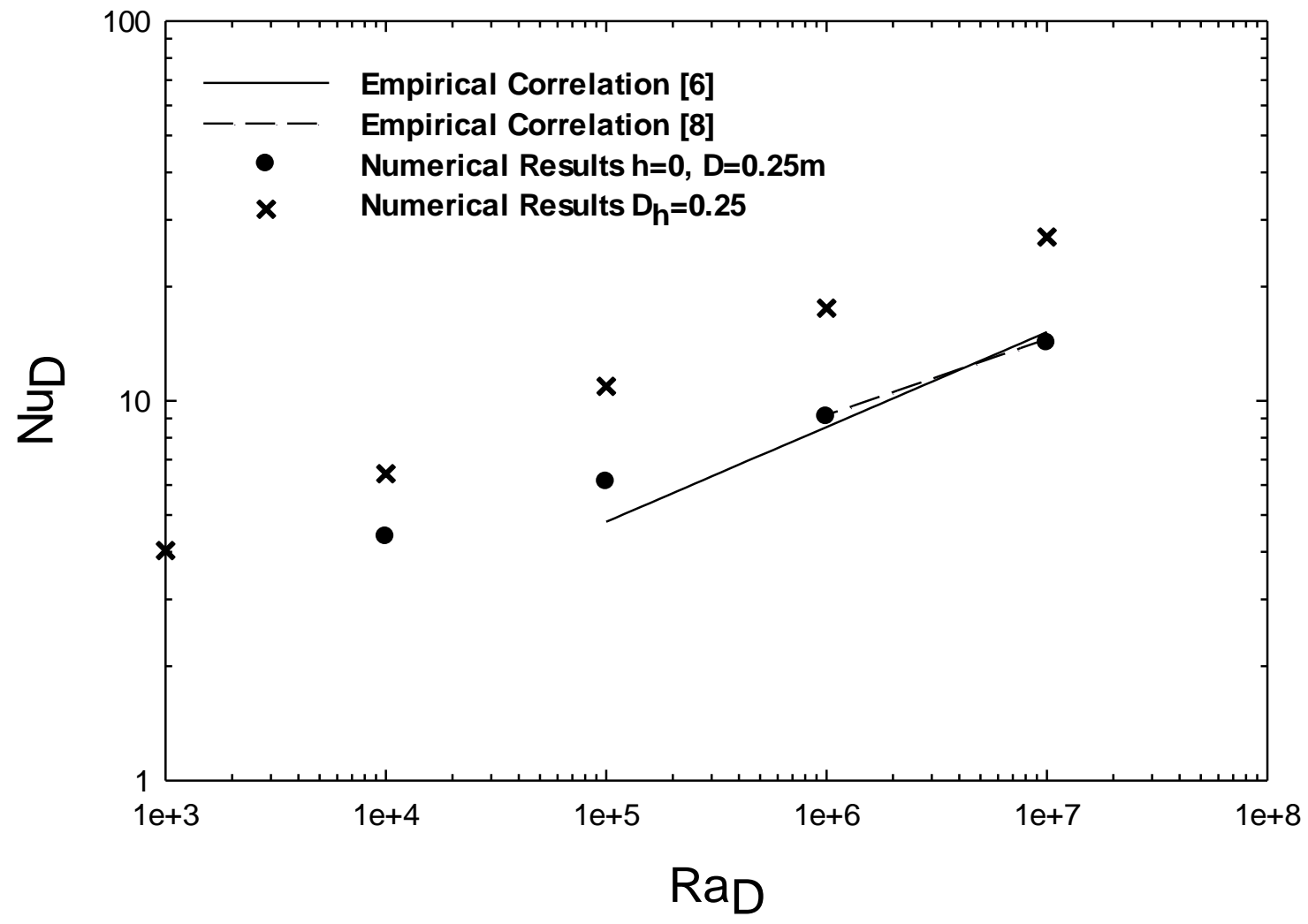

Figure 5 Variation of mean Nusselt number with Rayleigh number for $h=0$ and $D=0.25$ $\mathrm{m}$ (i.e., for a circular plate embedded in a horizontal adiabatic surface) and for a dimensionless cylinder diameter, $D_{h}=0.25$, for the case of a downward facing cylinder and a comparison of these results with those given by standard correlation equations for this situation 


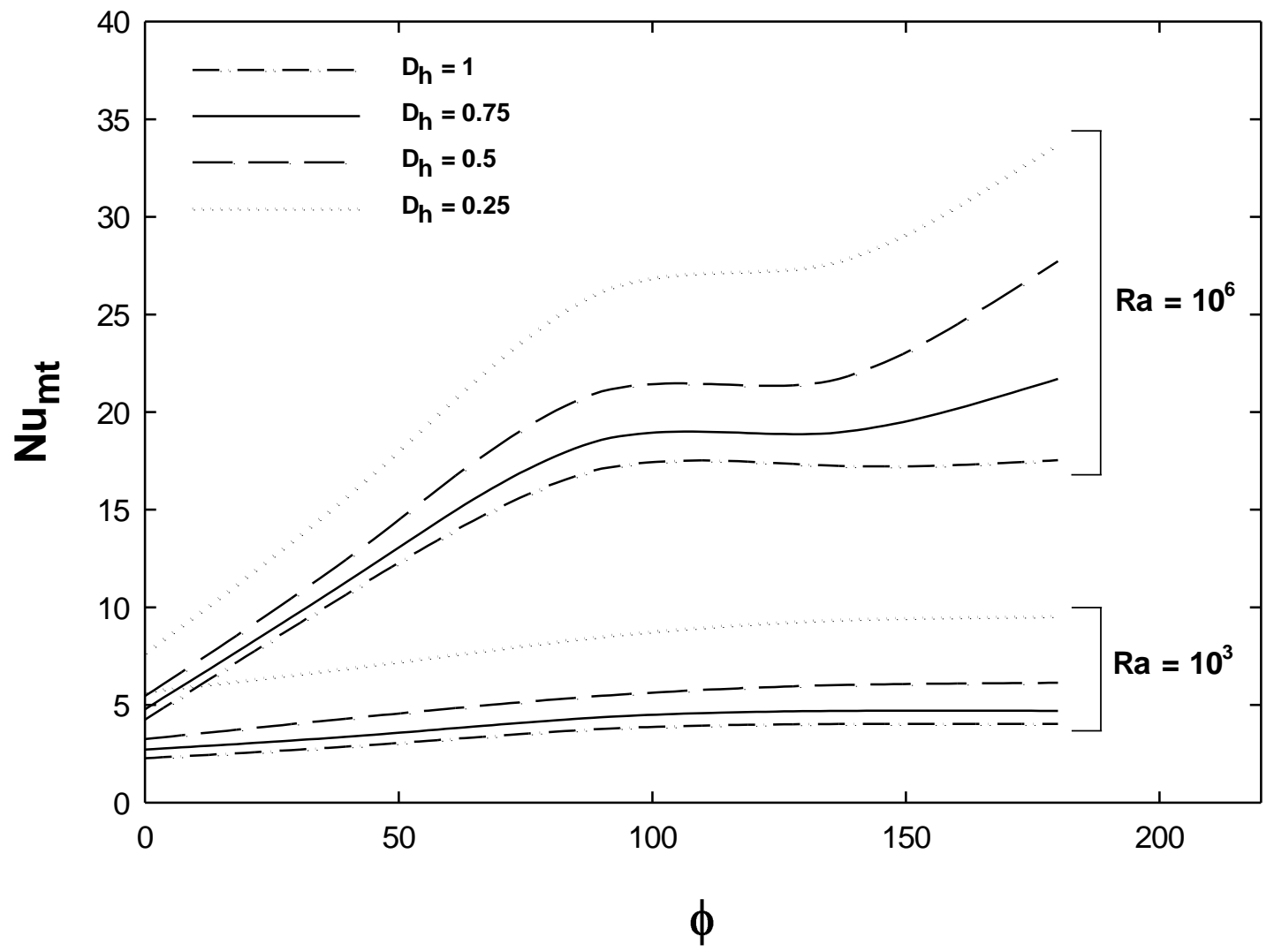

Figure 6 Variation of mean Nusselt number for the top surface of cylinder with $\phi$, for various values of Rayleigh number and dimensionless cylinder diameter, $D_{h}$ 


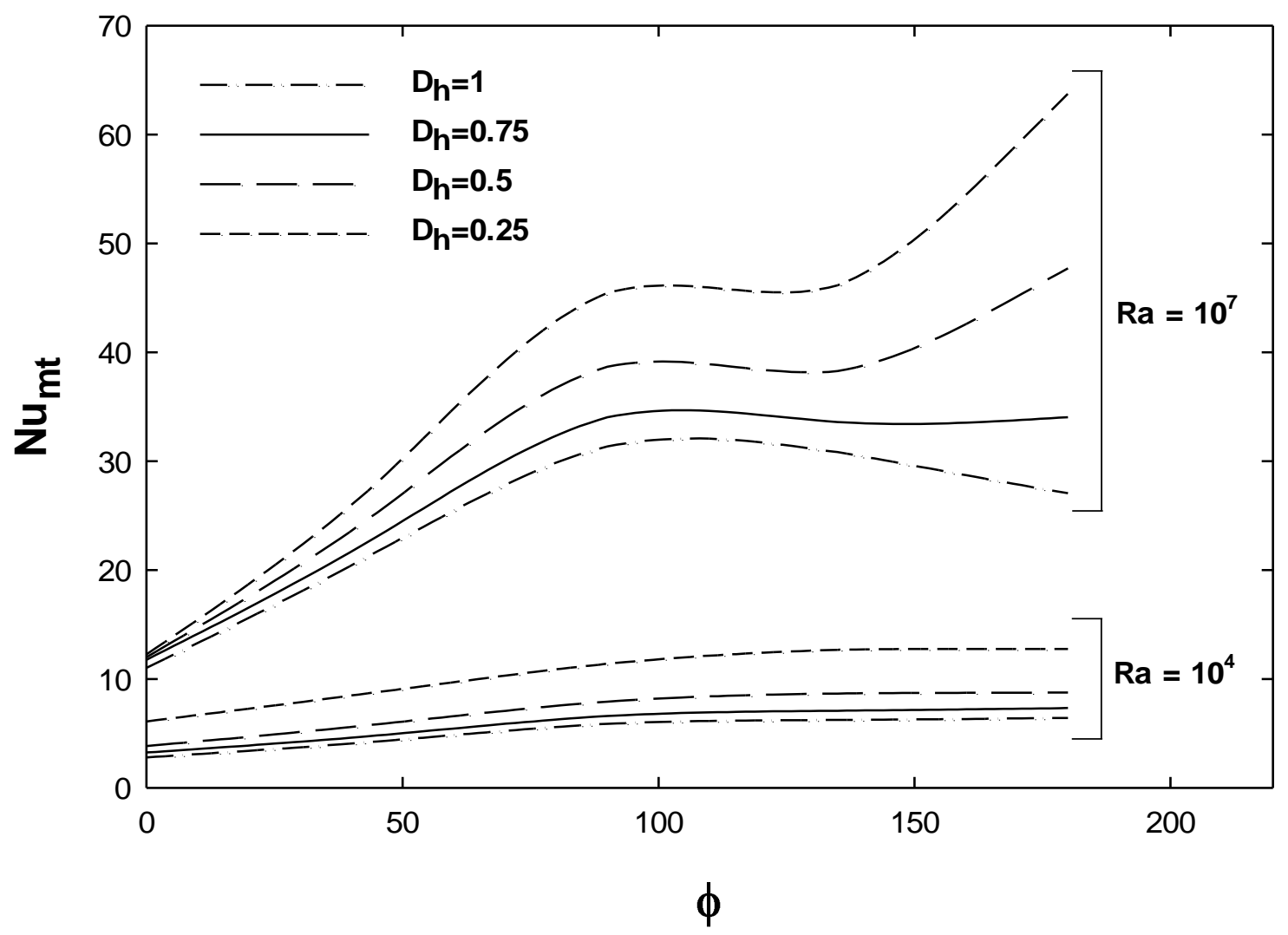

Figure 7 Variation of mean Nusselt number for the top surface of cylinder with $\phi$, for various values of Rayleigh number and dimensionless cylinder diameter, $D_{h}$ 


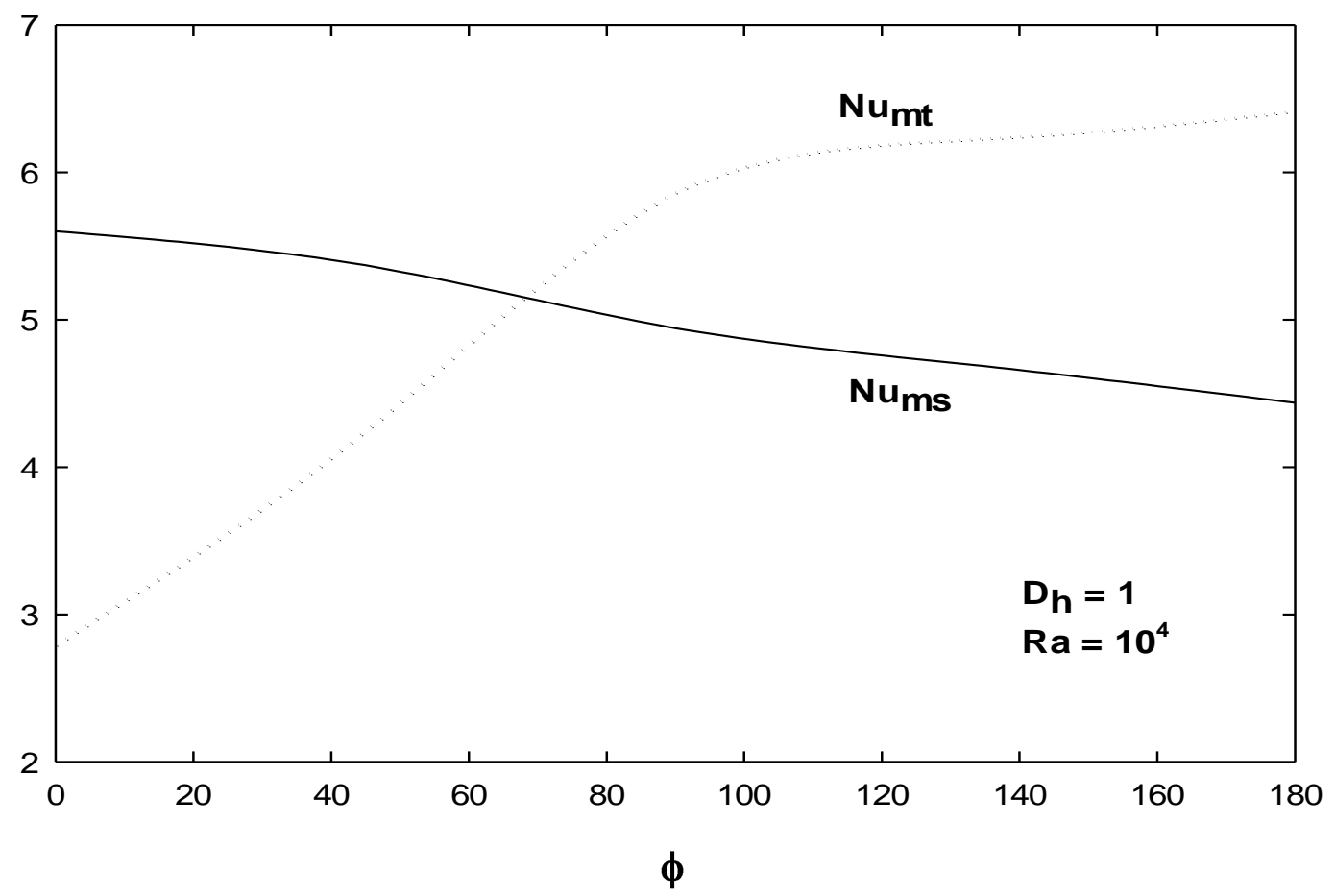

Figure 8 Variation of mean Nusselt number for the individual surfaces that make up the cylinder $N u_{\mathrm{ms}}$ and $N u_{\mathrm{mt}}$ with $\phi$ for $R a=10^{4}$ and $D_{h}=1$ 


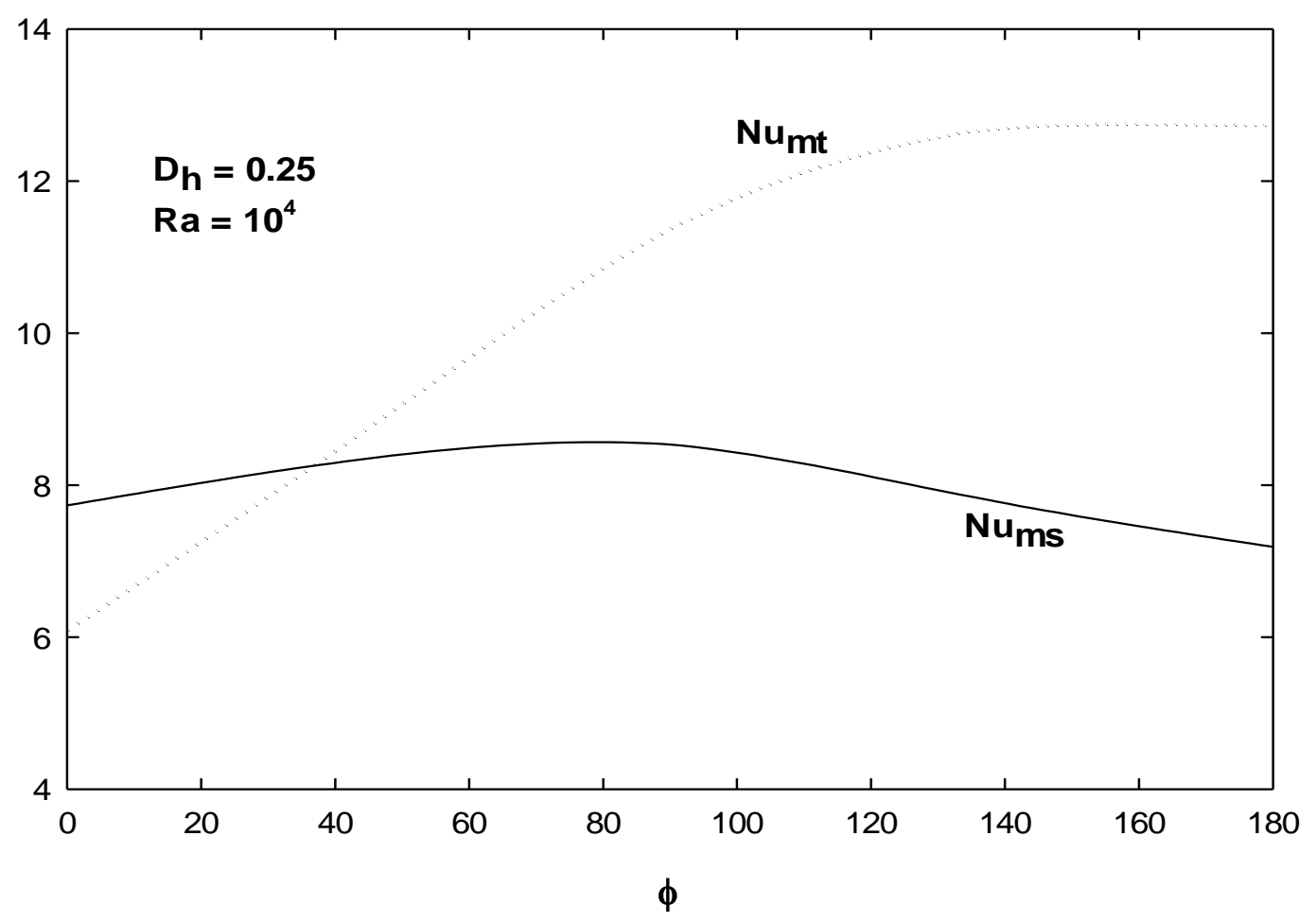

Figure 9 Variation of mean Nusselt number for the individual surfaces that make up the cylinder $N u_{\mathrm{ms}}$ and $N u_{\mathrm{mt}}$ with $\phi$ for $R a=10^{4}$ and $D_{h}=0.25$ 

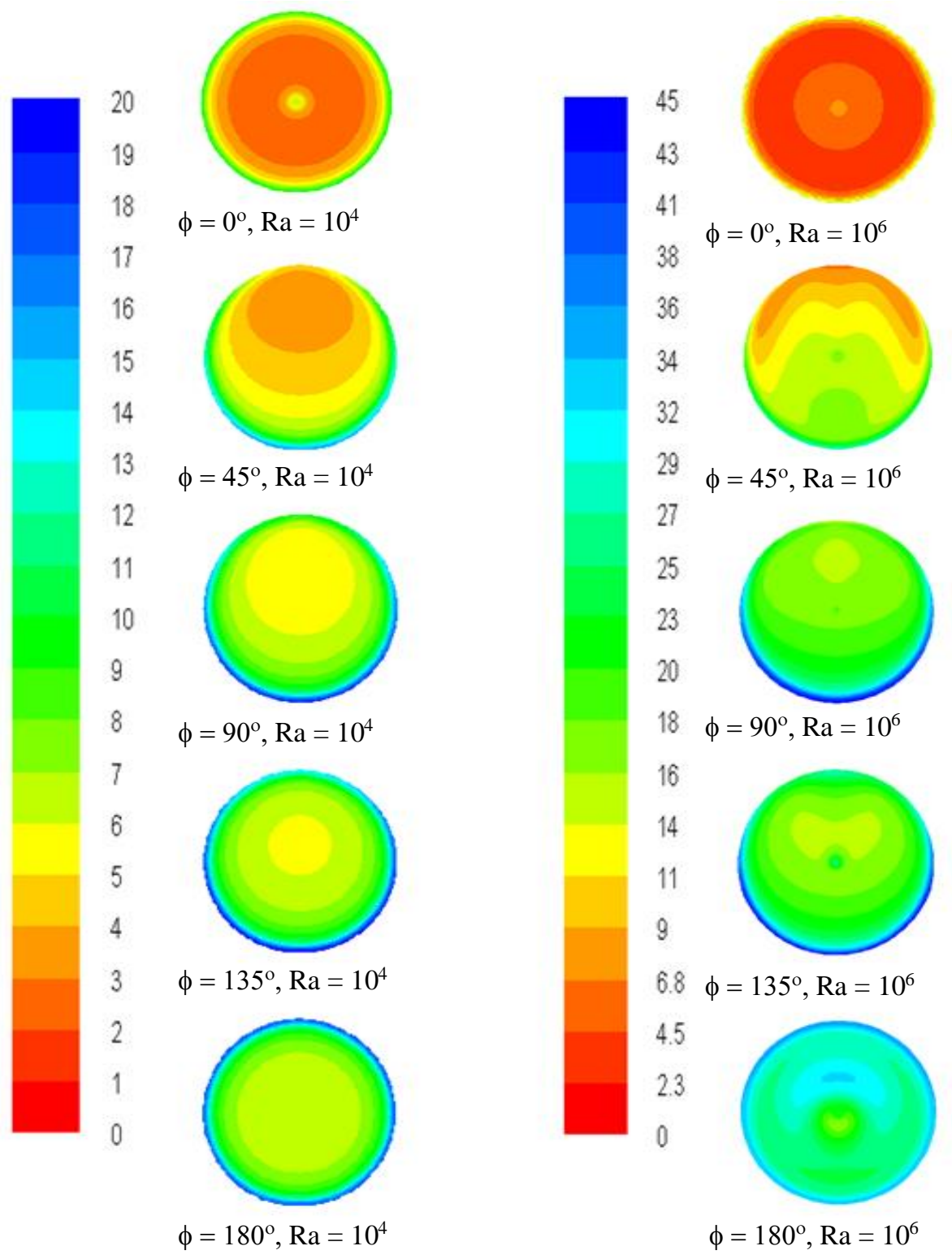

Figure 10 Variation of local Nusselt number $N u_{L(T o p)}$ based on $h$ over top side of the cylinder with different angles of inclination for $R a=10^{4}, R a=10^{6}$ and $D_{h}=0.5$ 


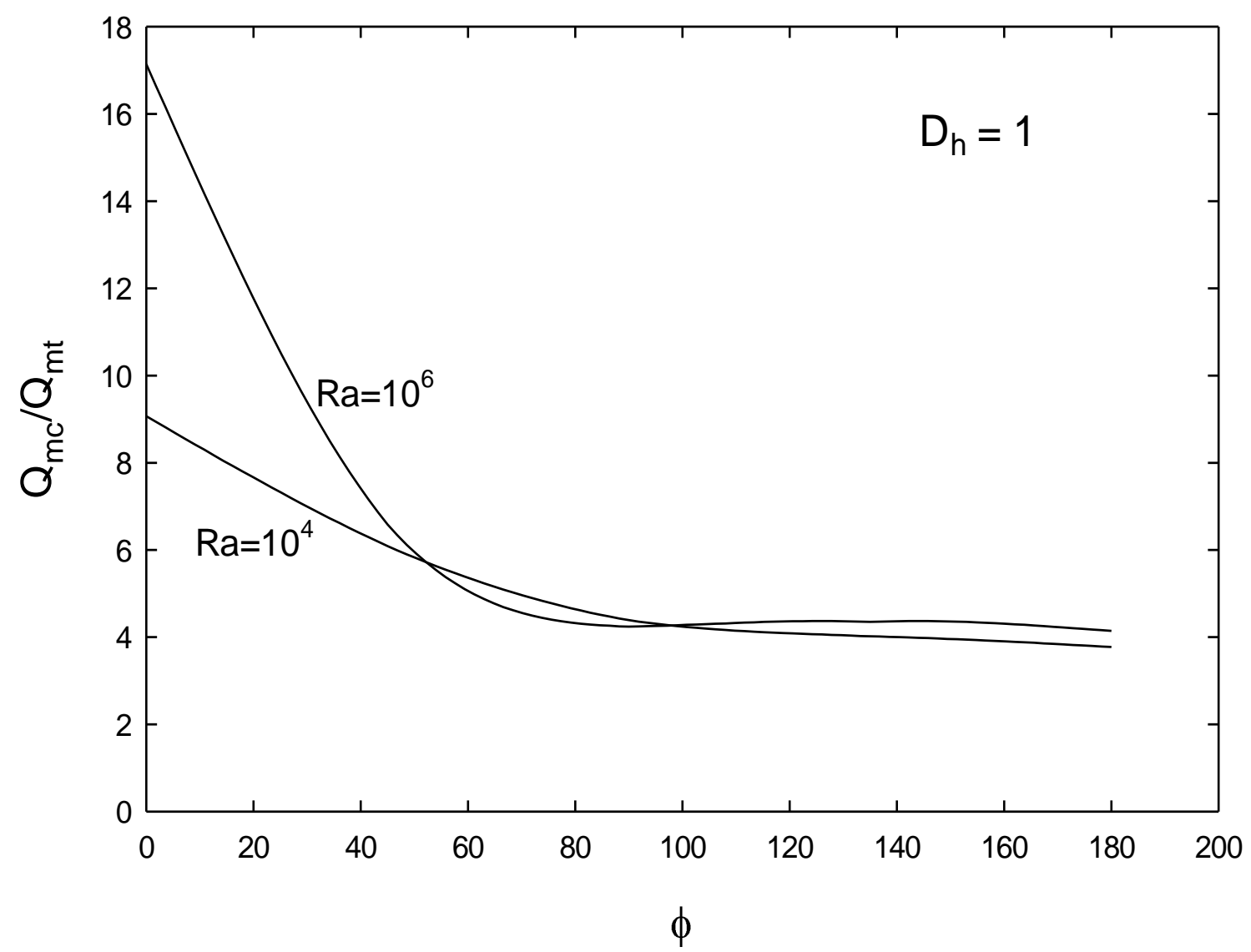

Figure 11 Variation of the ratio of the total heat transfer rate from the surfaces of the cylinder to the heat transfer rate from the top surface with angle of inclinations for $R a$ values of $10^{4}$ and $10^{6}$ and for $D_{h}=1$ 


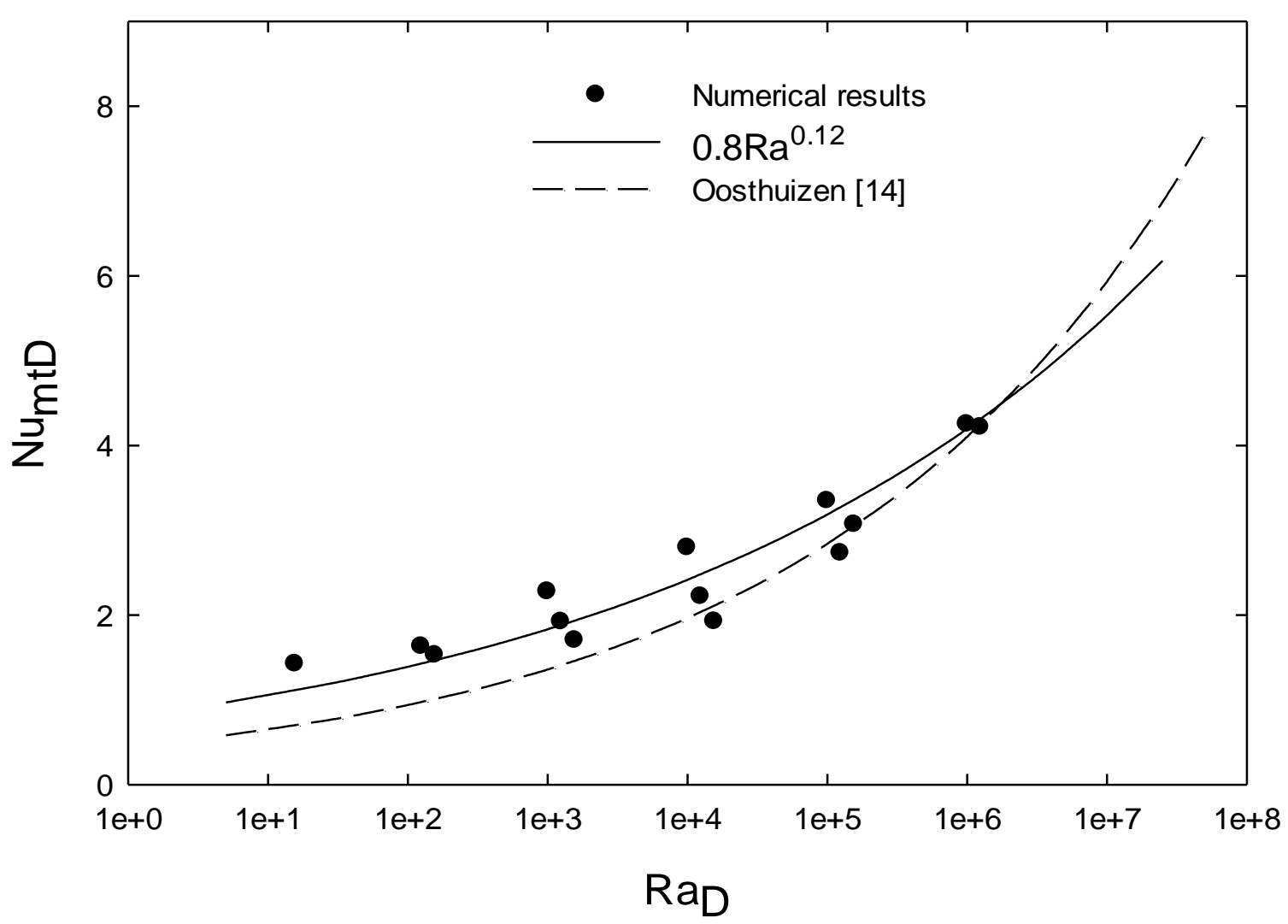

Figure 12 Comparison of correlation equations for the top surface of the cylinder for $\phi=0^{\circ}$ with the numerical results 


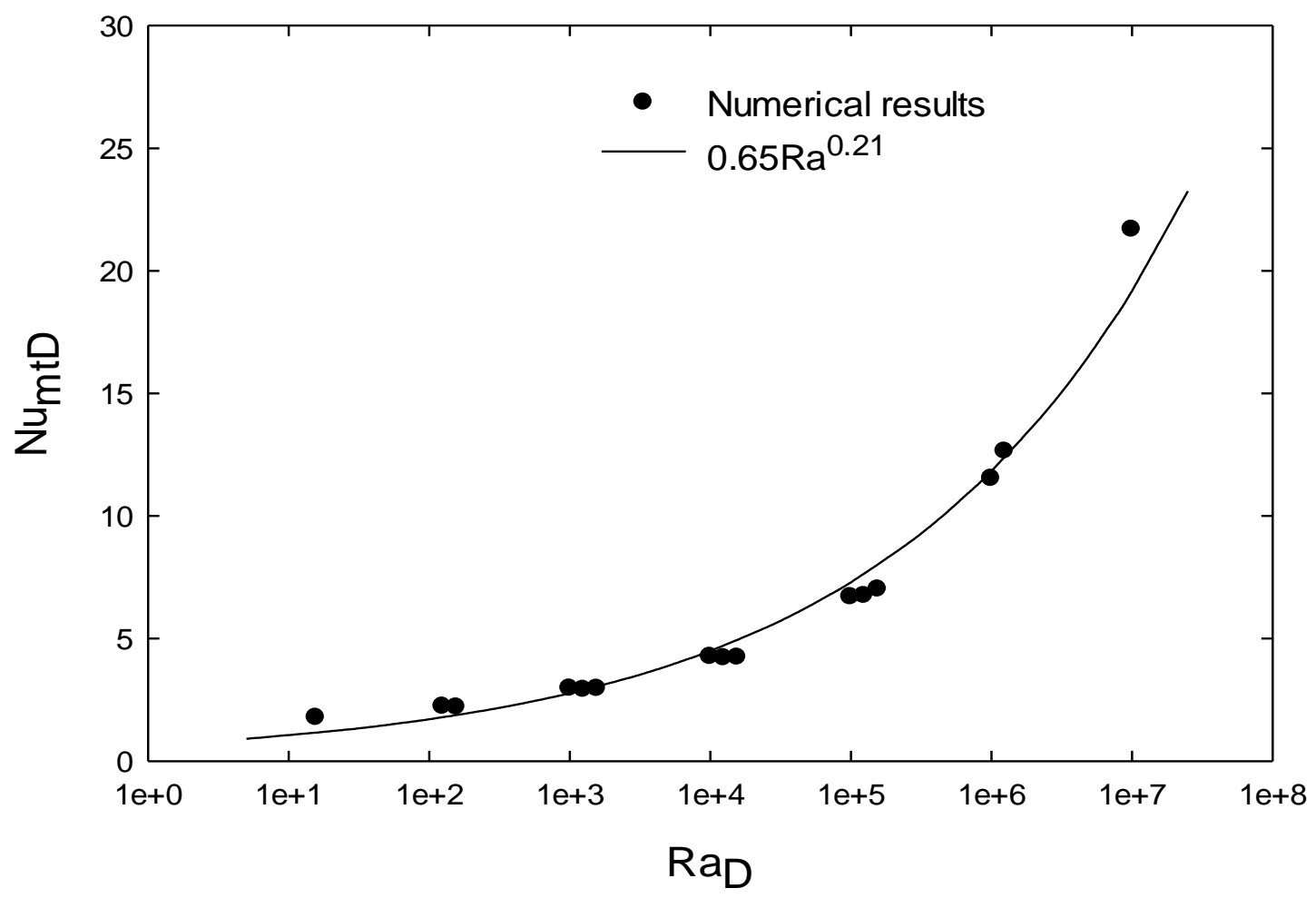

Figure 13 Comparison of correlation equation for the top surface of the cylinder for $\phi=45^{\circ}$ with the numerical results 


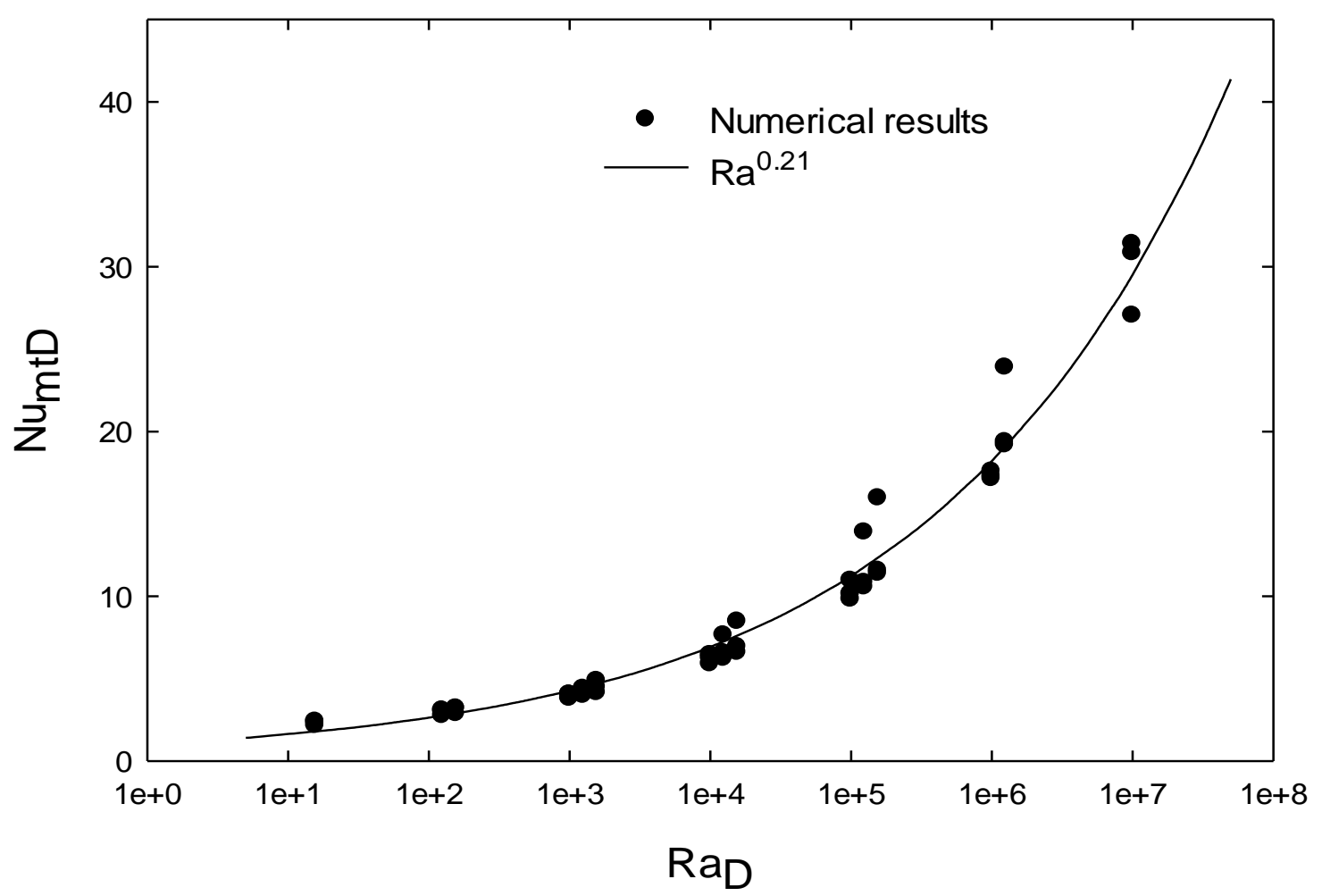

Figure 14 Comparison of correlation equation for the top surface of the cylinder for $\phi=90^{\circ}, 135^{\circ}$ and $180^{\circ}$ with the numerical results 


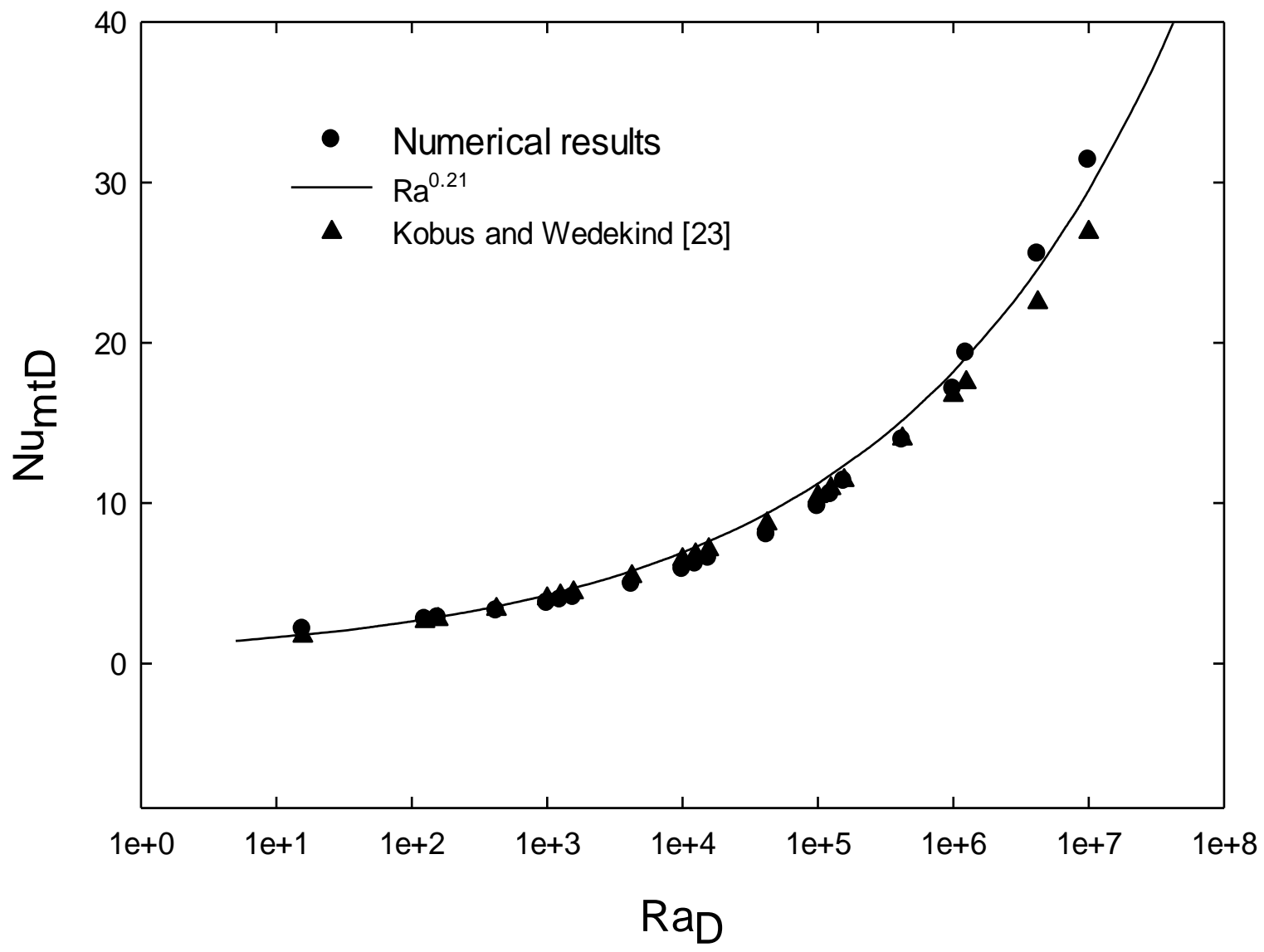

Figure 15 Comparison of correlation equations for the top surface of cylinder for $\phi=90^{\circ}$ with the numerical results 


\section{Abdulrahim Y. Kalendar \\ Brief Biography}

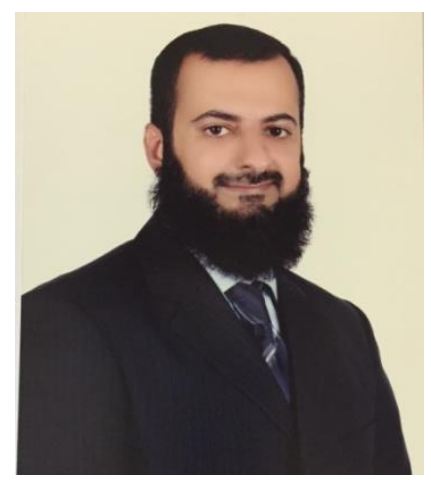

Abdulrahim Kalendar is currently assistant professor at College of Technological Studies in the mechanical power and refrigeration department since 1999, Kuwait. He graduated in mechanical engineering from Kuwait University (1998), obtained his M.Sc. from University of Colorado at Denver, USA (2002) and Ph.D. from Queen's University, Canada (2011). His primary research interests are in the area of refrigeration and aircondition, convective heat transfer and its applications in energy systems. He has undertaken many studies concerned with fundamental aspects of natural and combined convection and has also undertaken research concerned with various applications of heat transfer. He has published widely in the areas of his research and has also published two short books on aspects of natural convective heat transfer. 


\section{Sayed Karar \\ Brief Biography}

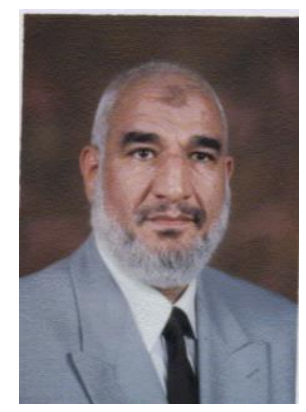

Sayed Karar received B.Sc., M.Sc. degrees in Mechanical Engineering from the University of El-Minia, Egypt and Ph.D. degree in Mechanical Engineering from the University of Sheffield, U.K. He joined the Department of Mechanical Engineering Power and Refrigeration at The Public Authority of Applied Education and Training after having taught for several years at the University of El-Minia. His primary research interests are in the area of fluid power control systems and its applications. He has undertaken many studies concerned with self-tuning and adaptive control of fluid power and dynamic systems. He has also undertaken research concerned with various applications of heat transfer. He has published a number of papers in the areas of his research. He has over thirty five years of teaching experience in the area of mechanical engineering and received a number of awards for his teaching. 
Ahmad Kalendar

Brief Biography

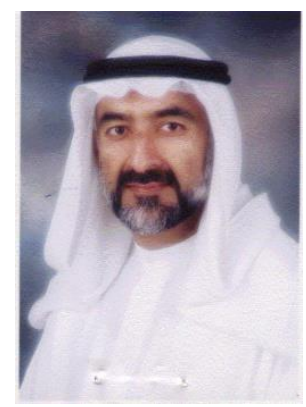

Ahmad Kalendar received B.Sc., M.Sc. degrees in Mechanical Engineering from North Carolina State University, Raleigh, NC, USA, and Ph.D. degree in heat transfer from Cardiff University at Wales, U.K. Hejoined the Department of Mechanical Engineering and Refrigeration at Kuwait College of Technology (The Public Authority of Applied Education and Training). His primary research interests are in the area of heat transfer, thermal science, desalination and RHVAC. Hehas undertaken many studies concerned with enhanced heat transfer and sea water desalination plants. Hehas published a number of papers in the areas of his research. He has over thirty years of teaching experience in the area of mechanical engineering. 


\section{PATRICK H. OOSTHUIZEN Brief Biography}

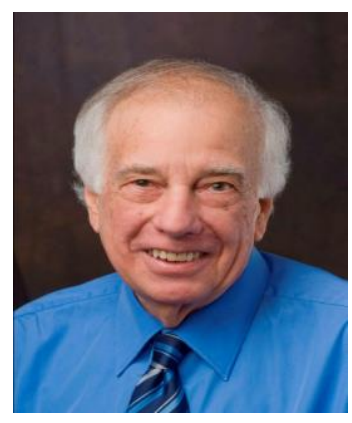

Patrick Oosthuizen received B.Sc., M.Sc., and Ph.D. degrees in Mechanical Engineering from the University of Cape Town and an M.A.Sc. degree in Aerospace Engineering from the University of Toronto. He joined the Department of Mechanical Engineering at Queen's University after having taught for several years at the University of Cape Town. His primary research interests are in the area of convective heat transfer and its applications in energy systems. He has undertaken many studies concerned with fundamental aspects of natural and combined convection and has also undertaken research concerned with various applications of heat transfer. He has published widely in the areas of his research and has also published textbooks on compressible fluid flow and convective heat transfer analysis and two short books on aspects of natural convective heat transfer. He has received several awards for his research and has also received a number of awards for his teaching. 